\title{
A Comparative Study in the Tribological Behavior of DLC Coatings Deposited by HiPIMS Technology with Positive Pulses
}

\author{
Jose A. García ${ }^{1,2, *}$, Pedro J. Rivero ${ }^{1,2}$, Eneko Barba ${ }^{3}{ }^{\complement}$, Ivan Fernández ${ }^{4}$, Jose A. Santiago ${ }^{4,5}$, \\ Jose F. Palacio ${ }^{6}$, Gonzalo G. Fuente ${ }^{6}$ and Rafael J. Rodríguez ${ }^{1,2}$ (I) \\ 1 Engineering Department, Public University of Navarre (UPNA), Campus Arrosadía S/N, \\ 31006 Pamplona, Spain; pedrojose.rivero@unavarra.es (P.J.R.); rafael.rodriguez@unavarra.es (R.J.R.) \\ 2 Institute for Advanced Materials (INAMAT), Public University of Navarre, Campus Arrosadía S/N, \\ 31006 Pamplona, Spain \\ 3 NUCAP, Polígono Ind. Arazuri-Orcoyen, Calle D, 2, 31170 Arazuri, Spain; Eneko.Barba@nucap.com \\ 4 Nano4Energy SL, José Gutiérrez Abascal 2, 28006 Madrid, Spain; ivan.fernandez@nano4energy.eu (I.F.); \\ joseantonio.santiago@nano4energy.eu (J.A.S.) \\ 5 PVT Plasma und Vakuum Technik GmbH, Rudolf-Diesel-Straße 7, 64625 Bensheim, Germany \\ 6 Centre of Advanced Surface Engineering, AIN, 31191 Cordovilla, Spain; jfpalacio@ain.es (J.F.P.); \\ gonzalo.garcia@unavarra.es (G.G.F.) \\ * Correspondence: joseantonio.garcia@unavarra.es; Tel.: +34-948169304
}

Received: 20 December 2019; Accepted: 22 January 2020; Published: 24 January 2020

\begin{abstract}
During the last few decades, diamond-like carbon (DLC) coatings were widely used for tribological applications, being an effective tool for improving the performance and the useful life of different machining tools. Despite its excellent properties, among which stand out a high hardness, a very low friction coefficient, and even an excellent wear resistance, one of the main drawbacks which limits its corresponding industrial applicability is the resultant adhesion in comparison with other commercially available deposition techniques. In this work, it is reported the tribological results of a scratch test, wear resistance, and nanoindentation of ta-C and WC:C DLC coatings deposited by means of a novel high-power impulse magnetron sputtering (HiPIMS) technology with "positive pulses". The coatings were deposited on 1.2379 tool steel which is of a high interest due to its great and wide industrial applicability. Finally, experimental results showed a considerable improvement in the tribological properties such as wear resistance and adhesion of both types of DLC coatings. In addition, it was also observed that the role of doping with $\mathrm{W}$ enables a significant enhancement on the adhesion for extremely high critical loads in the scratch tests.
\end{abstract}

Keywords: HiPIMS; positive pulse; DLC coatings; tribology; adhesion; wear resistance

\section{Introduction}

Diamond-like carbon (DLC) coatings are proven as promising and very efficient candidates for a wide variety of industrial applications due to their extraordinary mechanical performance, being one of the most well-known and consolidated surface treatments applied onto different types of substrates (mostly metals and ceramics) [1,2]. In this sense, DLC coatings are commonly applied as protective layers to cutting [3,4] and forming tools [5], although these coatings can also implemented in medical devices [6], automotive components [7], or electronics and optics applications [8], among others.

The combination of a high hardness and good wear resistance with a low coefficient of friction represents the main tribological reasons for using this type of Physical Vapor Deposition (PVD)-deposited DLC coating $[9,10]$. In addition, other important aspects such as a high elastic 
modulus, chemical inertness, and a high degree of biocompatibility can be also obtained with this type of coating [11]. However, its low adherence on metallic substrates, associated with the low density of chemical bonds and the high compressive stress, is its main drawback in comparison to other different deposition techniques, hindering further applicability in many fields of high-technology industries [12,13].

For instance, during metal stamping, the tools of the dies are subjected to large mechanical stresses as a result of the work done on the steel sheet used as a base material in the manufacturing. The pressure can be applied progressively or by percussion, for which presses and hammers are used. The molds involved in the operation are two steel stamps or dies, one of which slides through a guide while the other is fixed. In the case of standard parts, there are various partial solutions in terms of materials, and additional treatments in order to improve their properties and durability, which offer a highly contrasted stable behavior [14]. The importance of the continuous development of solutions to improve the performance of this type of tool is a key and essential factor for increasing the productivity of manufacturing processes [15]. According to this, different types of strategies such as chemical vapor deposition (CVD) or PVD coatings for high-load applications [16,17] were successfully developed, going from a combination of a thermochemical treatment (usually nitriding) with a thin layer obtained by cathodic-arc [18] to more recent strategies based on the combination of multilayers and composites of nanometric spacing $[19,20]$.

In this regard, although PVD DLC coatings present the abovementioned adhesion problem, these types of coatings are gaining great importance in the field of surface engineering, especially in cutting tools; thus, important research advances are focusing on obtaining a chemical link between DLC coatings and the reference metallic substrate, aiming to homogenize the stress distribution. According to this, new coating techniques were developed that greatly improve the adhesion, showing a combination of the excellent tribological and mechanical performance of DLC coatings with a high adherence. In recent works, different adhesion values related to DLC coatings were reported, showing the scratch mark at $20 \mathrm{~N}$ load [21] or at approximately $35 \mathrm{~N}$ load [22], although these values are low for the aforementioned industrial applications. Another alternative to increase the adhesion is based on a previous thermochemical pretreatment such as plasma nitriding [23], although this type of treatment could penalize the corrosion resistance of the metallic substrate [24]. However, a promising result was presented in Reference [25], where the deposition of multilayered coatings by combining both filtered cathodic vacuum arc and high-power impulse magnetron sputtering (HiPIMS) led to an improvement in the adhesion strength, going up to $63 \mathrm{~N}$. This aspect of the adhesion enhancement of DLC hard coatings by HiPIMS metal ion etching pretreatment was also observed in Reference [26]. In this work, an increase in the resultant adhesion, as well as in the wear resistance, of two different types of DLC coatings, such as tetrahedral amorphous carbon (ta-C) and tungsten carbide:carbon (WC:C), was achieved using a novel high-power impulse magnetron sputtering (HiPIMS) method that incorporates positive voltage pulses after the conventional HiPIMS discharge. This novel technology was studied in a previous work aiming to evaluate the effect of different positive voltage amplitudes in the corresponding mechanical properties of the DLC hard coatings [27], although no studies on the resultant adhesion were reported. Similarly, the role of metal dopants like Cr was recently investigated [28], showing that high contents of Cr within the DLC layer can lead to reduced internal stresses without any significant effect on the mechanical properties and clear improvement of the tribological behavior at higher temperatures, between $100{ }^{\circ} \mathrm{C}$ and $200{ }^{\circ} \mathrm{C}$. However, these studies were developed on softer substrates (SS304), and there is no available information on the adhesion of these coatings. The aim of this work is to evaluate the tribological and mechanical properties of DLC coatings deposited by HiPIMS with positive pulses on tool steels for industrial applications, where the adhesion of coatings is a critical parameter. 


\section{Experimental Procedure}

\subsection{Reference Substrate}

Samples of 1.2379 steel with a flat geometry, $30 \mathrm{~mm}$ in diameter, were used as reference substrates. All specimens were previously polished in order to obtain a final $R_{a}$ less than 0.2 microns. In addition, prior to any plasma treatment, the substrate surfaces were thoroughly cleaned following a sequence of steps consisting of ultrasonic washing with alkaline detergent (1\% Tickopurr R33), rinsing with de-ionized water, cleaning with isopropanol, and air-drying.

\subsection{Film Deposition Technique}

The deposition experiments were carried out in the industrial system $x$ Pro4C designed by PVT $\mathrm{GmbH}$. The system integrates, in a vacuum chamber of $0.51 \mathrm{~m}^{3}(680 \mathrm{~mm} \times 650 \mathrm{~mm} \times 1150 \mathrm{~mm})$, four cathodes designed with adjustable magnetic field configurations. Figure 1 schematically outlines a view of the chamber cross-section.

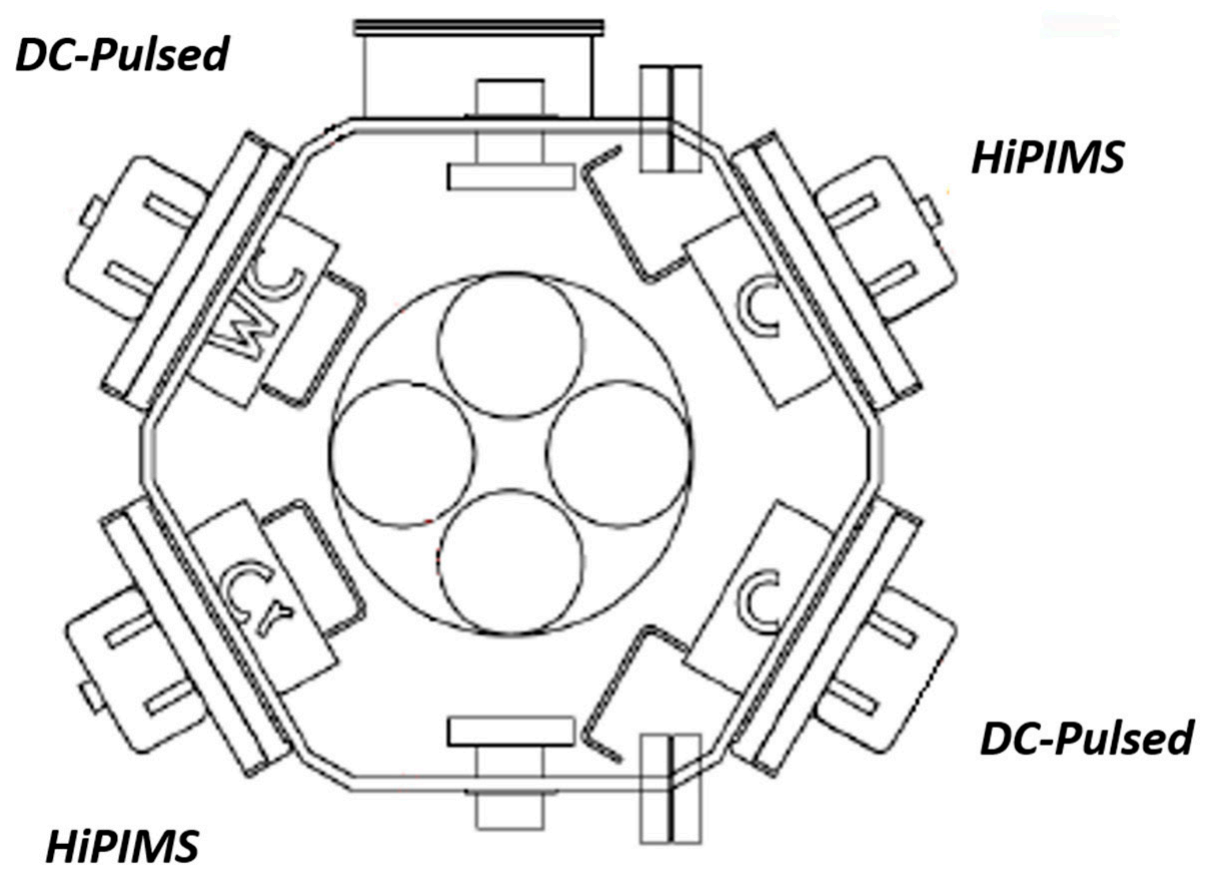

Figure 1. Process chamber horizontal cross-section.

The chamber is evacuated by two turbomolecular pumps and two double-stage rotary vane pumps, reaching a base pressure of $10^{-6} \mathrm{mbar}$. The four cathodes are incorporated in equidistance. For DLC coating deposition, one cathode is operated under unbalanced magnetron mode (UBM), while the other is operated under HiPIMS V+ mode, both carrying graphite targets. The third cathode is used for depositing a WC interlayer with a balanced magnetron configuration carrying a binder-free WC target. The fourth cathode is operated in HiPIMS mode carrying a Cr target.

The sequence of parameters used for the different substrate pretreatments, as well as for the deposition of the coatings, is briefly described below.

(1) Ar etching: An $\mathrm{Ar}^{+}$discharge was established at the substrates for $15 \mathrm{~min}$, using a direct current (DC)-pulsed bias voltage of $-500 \mathrm{~V}$ and a frequency of $150 \mathrm{kHz}$.

(2) Cr-HiPIMS deposition of a bonding layer: The target was operated in HiPIMS mode with the following parameters: pulsing time of $150 \mu \mathrm{s}$, repetition frequency of $300 \mathrm{~Hz}$, and an average power density of $5 \mathrm{~W} / \mathrm{cm}^{2}$. The substrate voltage bias was adjusted from $-750 \mathrm{~V}$ to $-50 \mathrm{~V}$. 
The deposition rate obtained for a three-fold rotation at a substrate voltage bias of $-50 \mathrm{~V}$ was $0.5 \mu \mathrm{m} / \mathrm{h}$.

(3) Deposition of the WC interlayer: WC was deposited in DC-pulsed mode with a power density of $7.5 \mathrm{~W} / \mathrm{cm}^{2}$, a frequency rate of $150 \mathrm{kHz}$, and a pulse width of $2.7 \mu \mathrm{s}$. The substrate was biased at $-50 \mathrm{~V}$. The deposition rate obtained for a three-fold rotation was $0.38 \mu \mathrm{m} / \mathrm{h}$.

(4) Deposition of the DLC coating: The power density of the pulses reached values up to $10 \mathrm{~W} / \mathrm{cm}^{2}$. DC-pulsed mode was applied at a repetition frequency of $150 \mathrm{kHz}$ and a pulse width of 2.4 $\mu \mathrm{s}$. HiPIMS mode was operated at a pulsing time of $150 \mu \mathrm{s}$, repetition frequency of $300 \mathrm{~Hz}$, and a positive pulse of $350 \mathrm{~V}$. A substrate voltage bias of $-50 \mathrm{~V}$ was applied. The deposition rate obtained for a three-fold rotation was $0.25 \mu \mathrm{m} / \mathrm{h}$.

\subsection{Thickness, Structural Analysis, and Profile Composition}

Once the coating fabrication was performed, the chemical composition profiles with their corresponding weight percentages, as well as the resultant thickness of the coatings, were analyzed by glow discharge optical emission spectrometry (GD-OES) using a JOBIN YVON 100000RF GD-OES equipment (HORIBA Instruments, Horiba, Kyoto, Japan) [29].

Raman characterization was performed in order to evaluate the structural properties of DLC films. Raman spectra were recorded using a Renishaw inVia micro-Raman spectrometer. An argon ion laser with a line of $532 \mathrm{~nm}$ was focused on the surface of the coatings with a power of $10 \mathrm{~mW}$. The measurement time was $10 \mathrm{~s}$, and spectra were accumulated 10 times in order to reduce the noise level. The obtained Raman spectrum was curve-fitted using two Gaussian functions, peaking at disordered (D-band) and graphite (G-band) modes. In addition, the thickness of the coatings was also corroborated by the CSM Calotest equipment (CSM Instruments) using a 30-mm-diameter stainless-steel ball and superfine diamond water suspension as the abrasive medium. Finally, in order to appreciate the compactness grade of the coatings, cross-section images were obtained by a HITACHI S4800 field-emission scanning electron microscope (FE-SEM) (HITACHI High-Technologies Corporation, Tokyo, Japan).

\subsection{Mechanical and Tribological Tests}

The adhesion between the coating and the substrate was measured with the help of a CSM REVETEST Scratch tester (Peseux, Switzerland) fitted with a Rockwell indenter (diamond cone of $0.2 \mathrm{~mm}$ of tip radius). The corresponding experimental parameters for the mechanical tests were a load rate of $100 \mathrm{~N} / \mathrm{min}$, a scratching speed of $100 \mathrm{~mm} / \mathrm{min}$, a final load of $100 \mathrm{~N}$, and a total test length of $5 \mathrm{~mm}$. Once the scratch tests were performed, three different critical loads (LC) were registered by looking to the variations of the different recorded signals during the scratch test (penetration of the indenter within the substrate, acoustic emission, coefficient of friction); then, the spots where the different events occurred were observed by optical analysis. The first critical load (LC1) occurred when the first cohesive failure was observed. The second critical load (LC2) occurred when the first adhesive failure was observed, whereas the third critical load (LC3) was established when a total delamination of the coating was performed or when a critical defect was clearly observed in the reference substrate.

In addition, another method to determine the coating adherence is based on the observation of Rockwell C indentation test (Ludwigshafen, Germany), known as Daimler Benz Test. According to this, a conical diamond indenter is used to penetrate the corresponding coating surface, and, as a result, a massive plastic deformation of the reference substrate is obtained, which can fracture the coating. Then, conventional optical microscopy is used to evaluate the aspect of the damaged coated sample following a chart which shows different grades of failure [30].

Microtest equipment (Madrid, Spain) in pin-on-disc configuration was used for the tribomechanical tests. The coefficient of friction (COF) was measured using 10- and 12-mm-diameter alumina balls loaded at 40 N, $200 \mathrm{rpm}$, and 20,000 cycles. The generated wear tracks were measured by confocal 
microscopy (Sensofar, Terrasa, Barcelona, Spain), and the loss volume and wear evaluation were determined according to ASTM99.

Nanohardness measurements were performed with a Hysitron Triboindenter TI950 (Hysitron-Bruker, Eden Prairie, MN, USA) fitted with a Berkovich tip with an end radius of $150 \mathrm{~nm}$. Hardness and Young's modulus were obtained according to the method of Oliver and Pharr [31,32].

\section{Results}

\subsection{Thickness and Composition}

First of all, Calotest measurements were performed with the aim of determining the resultant thickness of the coatings, as can be appreciated in Figure 2. According to this, the samples composed of a ta-C layer showed a thickness of approximately $1.65 \mu \mathrm{m}$, whereas the samples composed of WC:C layer showed a thickness of $2 \mu \mathrm{m}$. These results are also in agreement with the results shown by the glow discharge optical emission spectrometry (GD-OES) of Figure 3 and the cross-section SEM results of Figure 4.

Firstly, according to the GDOES results, the ta-C layer was slightly thicker than $1.5 \mu \mathrm{m}$, showing a weight percentage concentration in C of $100 \%$ up to $0.75 \mu \mathrm{m}$ in depth, followed by a WC layer of another $0.75 \mu \mathrm{m}$ with decreasing weight content of carbon across the layer. Finally, aiming to improve the adhesion to the reference substrate, an anchoring layer of $0.2 \mu \mathrm{m}$ in chromium was also observed. As for the WC:C coating, it was made of two different layers: a top carbon layer doped with $\mathrm{W}$ of around $0.75 \mu \mathrm{m}$ and containing $55 \% \mathrm{C}$ and $45 \% \mathrm{~W}$ in weight (95\% C and $5 \% \mathrm{~W}$ approximately in at.\%), followed by a transition layer of around $1 \mu \mathrm{m}$ in thickness, containing mainly $\mathrm{W}$, with decreasing content of $C$ from around $55 \%$ in weight down to less than $5 \%$ across the layer, as can be observed in Figure $3 \mathrm{~b}$. Finally, a chromium layer of $0.2-0.3 \mu \mathrm{m}$ was detected before reaching the reference substrate.

Complementarily, cross-section SEM images (see Figure 4) demonstrate the presence of homogeneous, continuous, and compact coatings for both types of layers.
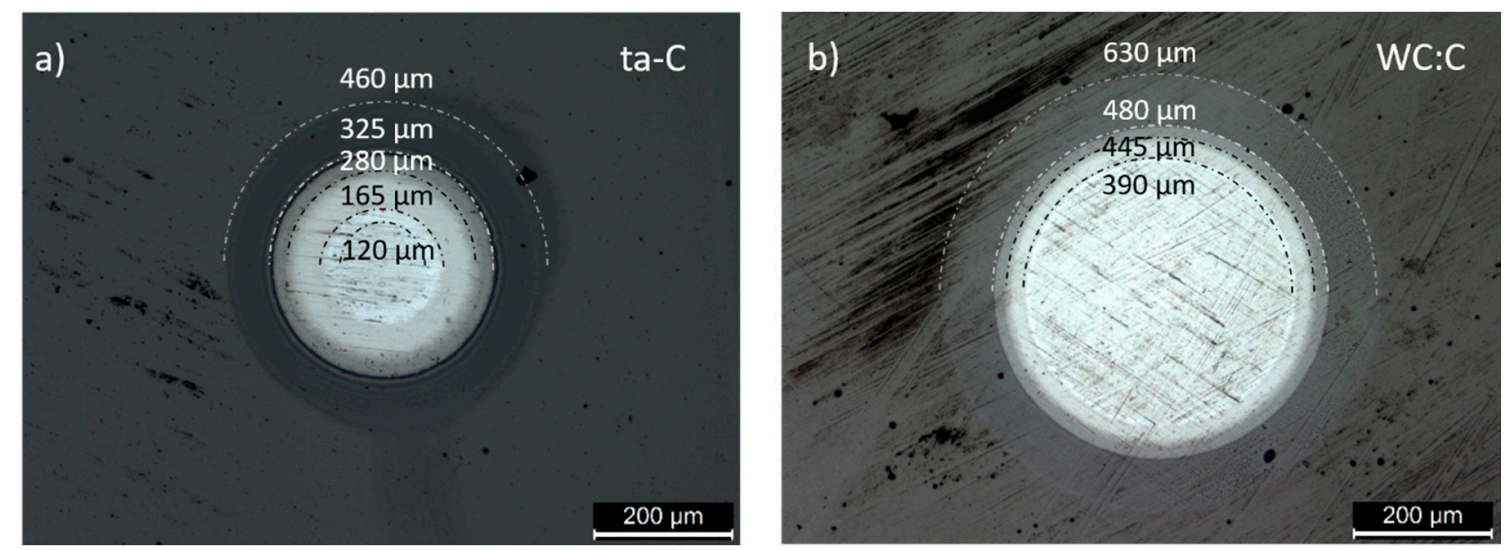

Figure 2. Calotest craters used to determine the resultant thickness for the ta-C coating (a) and sample coated by WC:C layer (b). The different numbers correspond to the different diameters of the rings exposed after the abrasion of the coating with the 30-mm balls used for the calculation of the different thicknesses. According to this method, the total thickness for the WC:C was around $2 \mu \mathrm{m}$, and the total thickness of the ta-C coating was $1.65 \mu \mathrm{m}$. 
a)

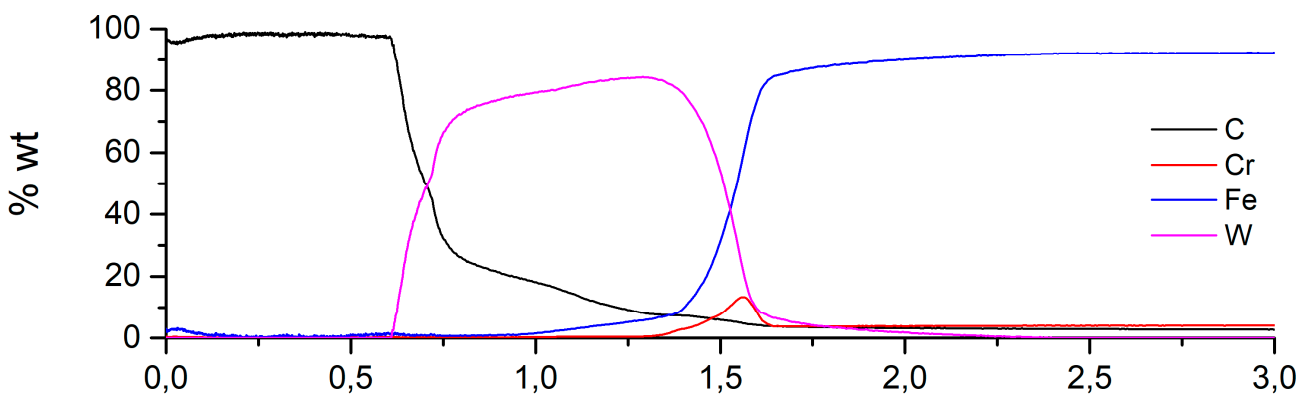

b)

Depth $(\mu \mathrm{m})$

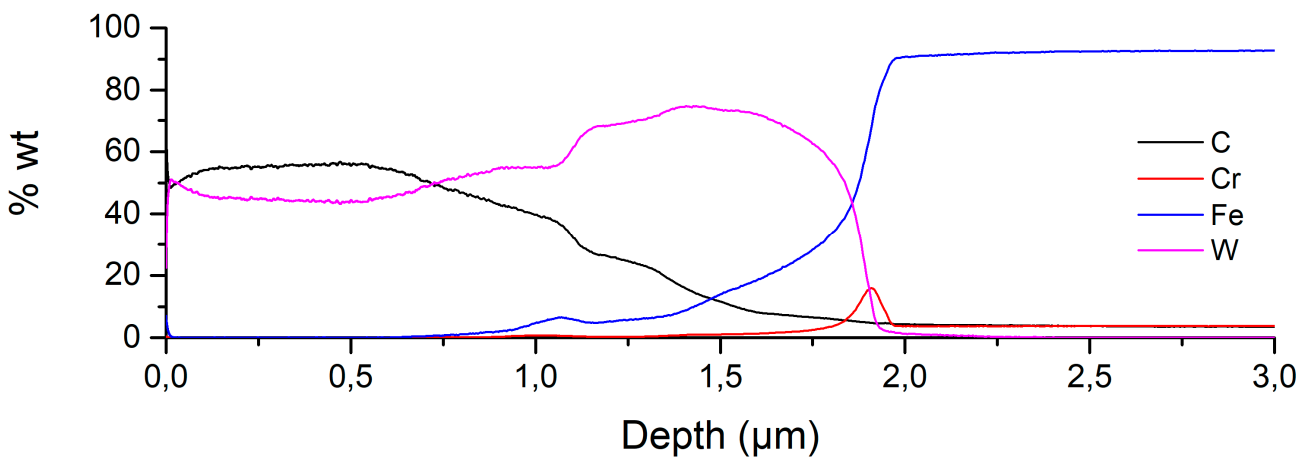

Figure 3. Glow discharge optical emission spectrometry (GD-OES) concentration profiles in the sample of ta-C coating (a) and WC:C coating $(\mathbf{b})$.

a)
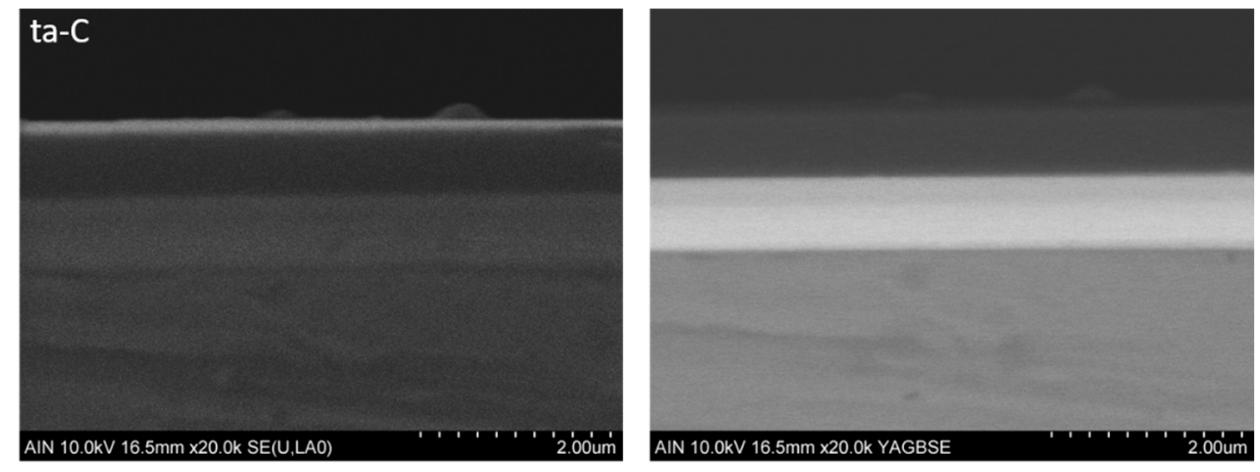

b) WC:C
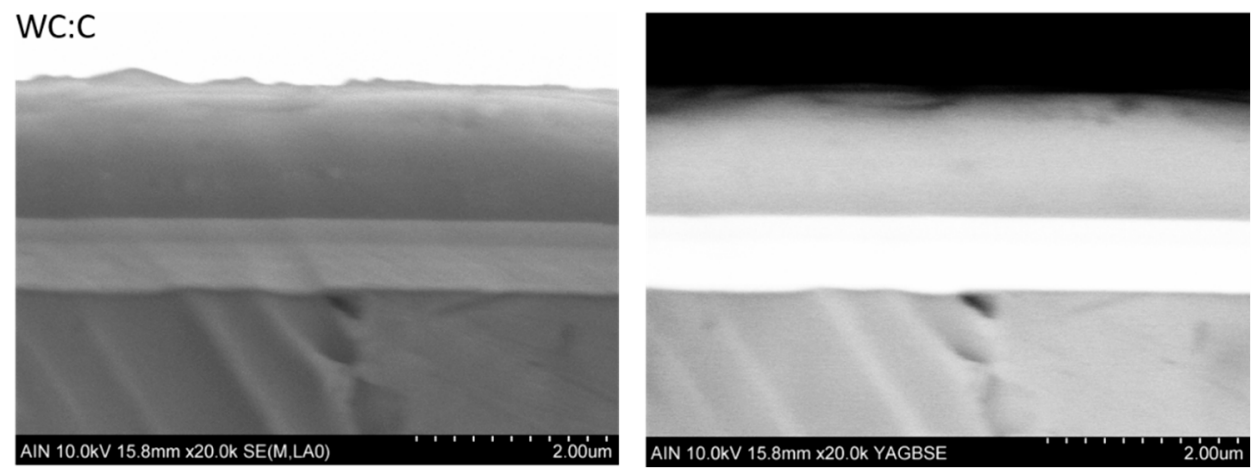

Figure 4. Cross-section SEM images for the sample of ta-C coating (a) and WC:C coating (b). On the left, the secondary electron signal (SE) images give some topographic information; on the right, the backscattered electron signal (BSE) images provide chemical contrast from the elements of the coatings.

In Figure 5a, the Raman spectrum related to the ta-C and WC-C coatings is shown. Characteristic D- and G-bands of carbon were identified (by fitting of the Raman spectra using two Gaussian functions) 
around $1360 \mathrm{~cm}^{-1}$ and $1540 \mathrm{~cm}^{-1}$, respectively (Figure $5 \mathrm{~b}, \mathrm{c}$ ). The Raman spectrum exhibits broadening and overlapping of the two bands, indicating a disordered amorphous carbon structure. For visible excitation (532 nm in our case), the ratio of $\mathrm{I}_{\mathrm{D}} / \mathrm{I}_{\mathrm{G}}$ was 1.0 and the full width at half maximum (FWHM) (G) had a value of 156.89 for ta-C, while the ratio of $\mathrm{I}_{\mathrm{D}} / \mathrm{I}_{\mathrm{G}}$ was 1.25 for WC:C, with an $\mathrm{FWHM}(\mathrm{G})$ of 126.95. According to the literature, the $\mathrm{I}_{\mathrm{D}} / \mathrm{I}_{\mathrm{G}}$ ratio is proportional to the number and clustering of rings, and it is especially sensitive to the number of ordered rings in the stage 2-3 transition [32]. A decrease in the intensity of the D-peak would then be associated with a gradual change in $s p^{2}$ sites from rings to chains and to the presence of $s p^{2}$ dimers embedded in the $s p^{3}$ matrix. The $\pi$ states become increasingly localized on olefinic chains. Olefinic bonds are shorter than aromatic bonds and have higher vibration frequencies, which results in $\mathrm{I}_{\mathrm{D}} / \mathrm{I}_{\mathrm{G}}$ ratios close to zero. This effect usually implies enhanced $s p^{3}$ content [33].

a)
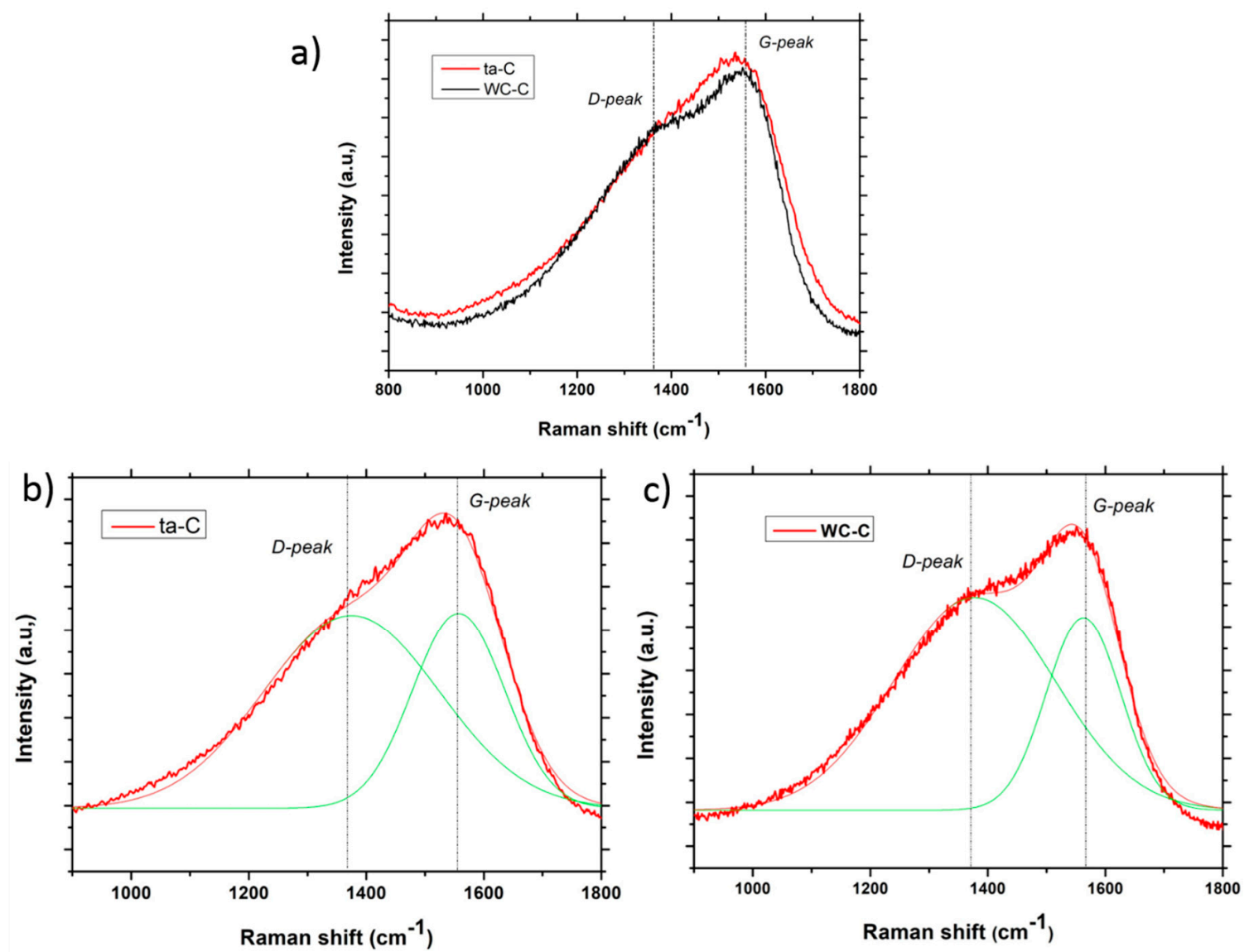

Figure 5. (a) Raman spectra of the ta-C and WC:C samples. (b) Fitting of ta-C sample. (c) Fitting of WC:C sample.

\subsection{Nanoindentation Test}

Nanoindentation tests up to a final load of $10 \mathrm{mN}$ are represented in Figure 6. The experimental results demonstrate that a specific hardness of $30.65 \mathrm{GPa}$ was obtained for the ta-C layer (green line), whereas a hardness of $17.57 \mathrm{GPa}$ was reached for the WC:C layer (blue line).

The results of nanoindentation related to the WC:C coatings are similar to the results of Sun et al. [34], showing a value of around $18 \mathrm{GPa}$. However, higher values of nanohardness were reported by Duminica et al. [22], which were found to be about 21-23 GPa. An important aspect to remark is that these DLC values were lower than those obtained by the ta-C layer (30.65 GPa).

In addition, the curves of load and unload showed a high elastic component for both types of coatings, although the final depth was significantly greater for the WC:C coating in comparison with the ta-C coating. Table 1 summarizes the corresponding hardness values, the Young modulus 
values, and the relationship between the hardness and modulus $\left(H^{3} / E^{2}\right)$ for both types of DLC coatings derived from the experimental data of the nanoindentation tests. Finally, according to this, a very interesting and promising result was the value of $H^{3} / E^{2}$ for the ta-C DLC coating (0.45) in comparison with the WC:C DLC coating (0.15), which is an important parameter directly associated with the plastic deformation resistance.

Table 1. Summary of the experimental data derived from the nanoindentation curves including the resultant hardness $(H)$, Young modulus $(E)$, and their relationship $H^{3} / E^{2}$. DLC-diamond-like carbon.

\begin{tabular}{cccc}
\hline Type of DLC Coating & Hardness (GPa) & Young Modulus (GPa) & $\boldsymbol{H}^{\mathbf{3}} / \boldsymbol{E}^{\mathbf{2}}$ \\
\hline ta-C & $30.65 \pm 1.07$ & $251.2 \pm 3.71$ & 0.45 \\
WC:C & $17.57 \pm 0.56$ & $188.2 \pm 3.45$ & 0.15 \\
\hline
\end{tabular}

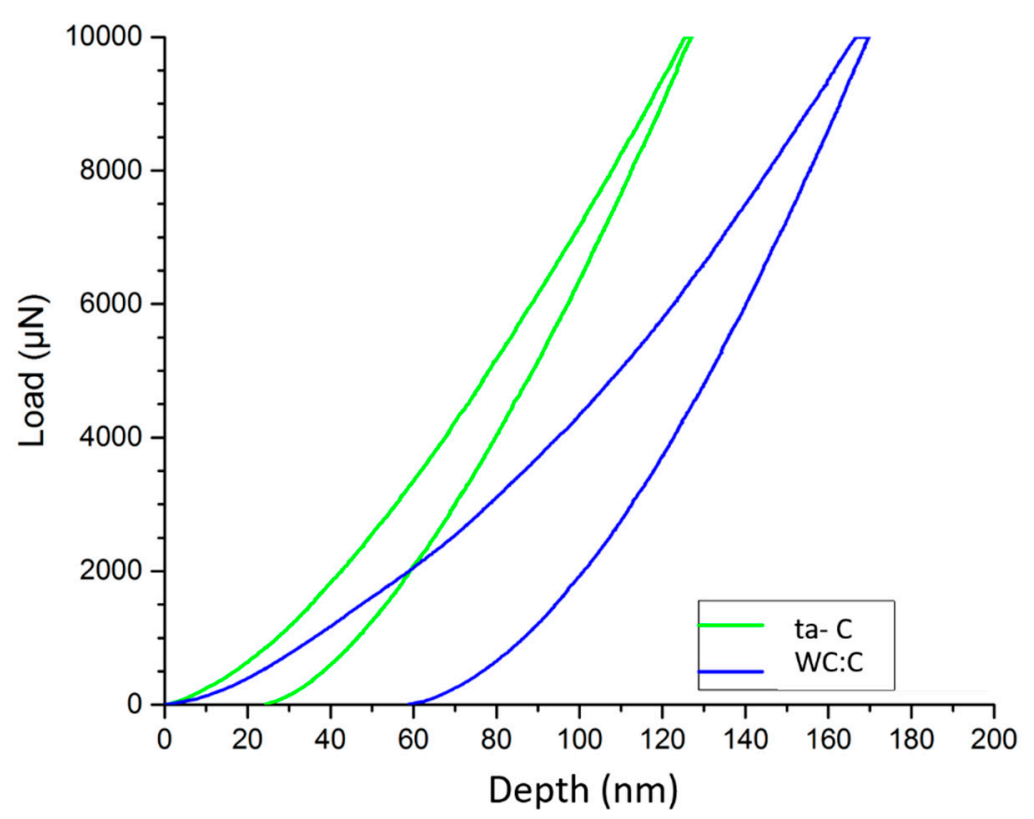

Figure 6. Nanoindentation curves for a specific final load of $10 \mathrm{mN}$ in the ta-C coating (green plot) and WC:C coating (blue plot).

\subsection{Adhesion Test}

First of all, for a better understanding of the mechanical response and the adhesion properties of the DLC coatings, scratch tests were carried out on both coatings (Figure 7 for ta-C coating and Figure 8 for WC:C coating), where different failure modes were evaluated along the scratch, and the loads at which they occurred were registered. The experimental results derived from these adhesion tests were very positive, showing a similar behavior in the resistance to cohesive failure, but displaying significant differences between both types of DLC coatings in their LC2 and LC3 values. In both figures, the acoustic emission (AE) and the coefficient of friction (COF) are represented, which establish a relationship between the normal and tangential forces, respectively. According to this, on one hand, in Figure 7, the ta-C DLC coating presented the first cohesive failure (LC1) at about $12 \mathrm{~N}$ and the first adhesive failure (LC2) at around $20 \mathrm{~N}$, whereas the appearance of the substrate (LC3) occurred at around 50 N. On the other hand, in Figure 8, it can be clearly observed that the adhesion related to the WC: $C$ coating was better than the ta-C coating because LC2 was defined at around $40 \mathrm{~N}$, whereas the last coating between the indenter and substrate (LC3) appeared at about $60 \mathrm{~N}$. These results of the adhesion test are higher than those reported in Reference [22], showing an LC3 value of $35 \mathrm{~N}$, or in Reference [23], with a value of 16 up to $40 \mathrm{~N}$ in non-nitrided steels as a function of the bias voltage. In 
this sense, by using different biases, similar results were reported in Reference [25], with an LC3 value of $55 \mathrm{~N}$, although this work presented multilayered coatings.

A summary of the different critical loads (LC1, LC2, and LC3) for both types of DLC coatings is presented in Table 2.

Table 2. Summary of the experimental data derived from the scratch tests with the corresponding values of critical load (LC1, LC2, and LC3) for both types of DLC coatings.

\begin{tabular}{cccc}
\hline DLC Coating & LC1 & LC2 & LC3 \\
\hline ta-C & $11.72 \mathrm{~N}$ & $18.86 \mathrm{~N}$ & $49.39 \mathrm{~N}$ \\
WC:C & $10.29 \mathrm{~N}$ & $40.87 \mathrm{~N}$ & $57.89 \mathrm{~N}$ \\
\hline
\end{tabular}
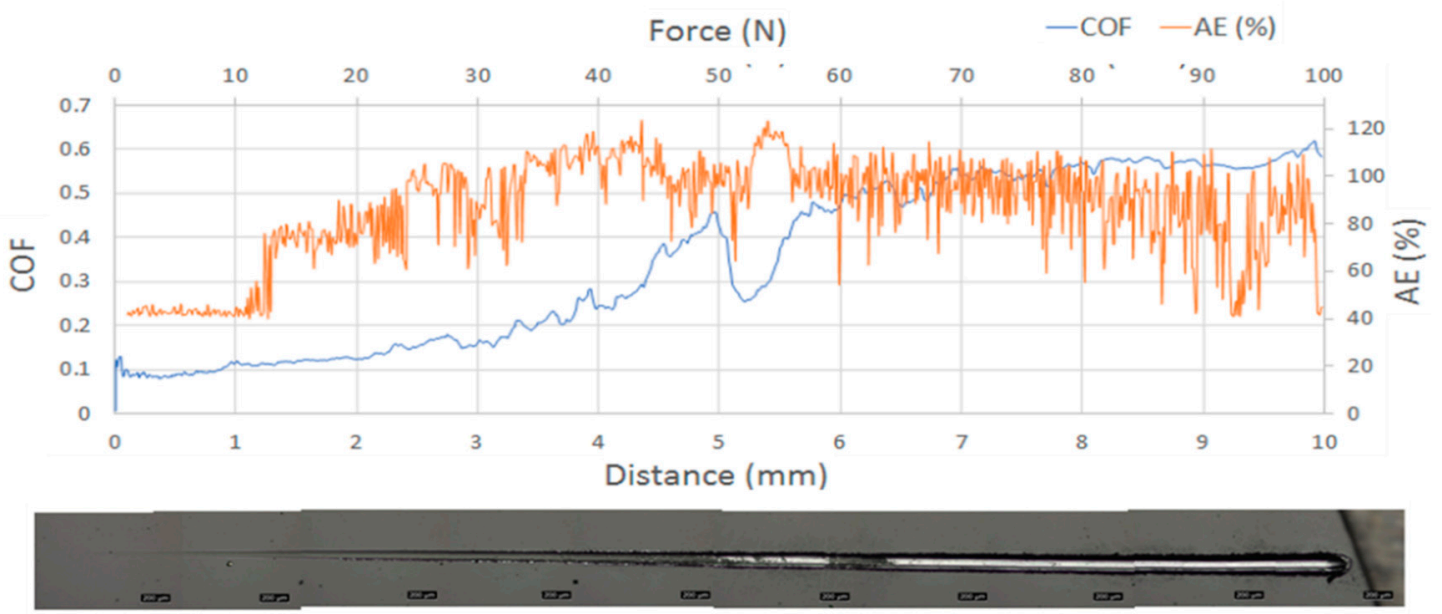

Figure 7. Nanoscratch test for ta-C coating. Evolution of the coefficient of friction (COF, blue plot) and the acoustic emission (AE, orange plot) vs. the indenter displacement, and optical micrograph of the scratch tracks.
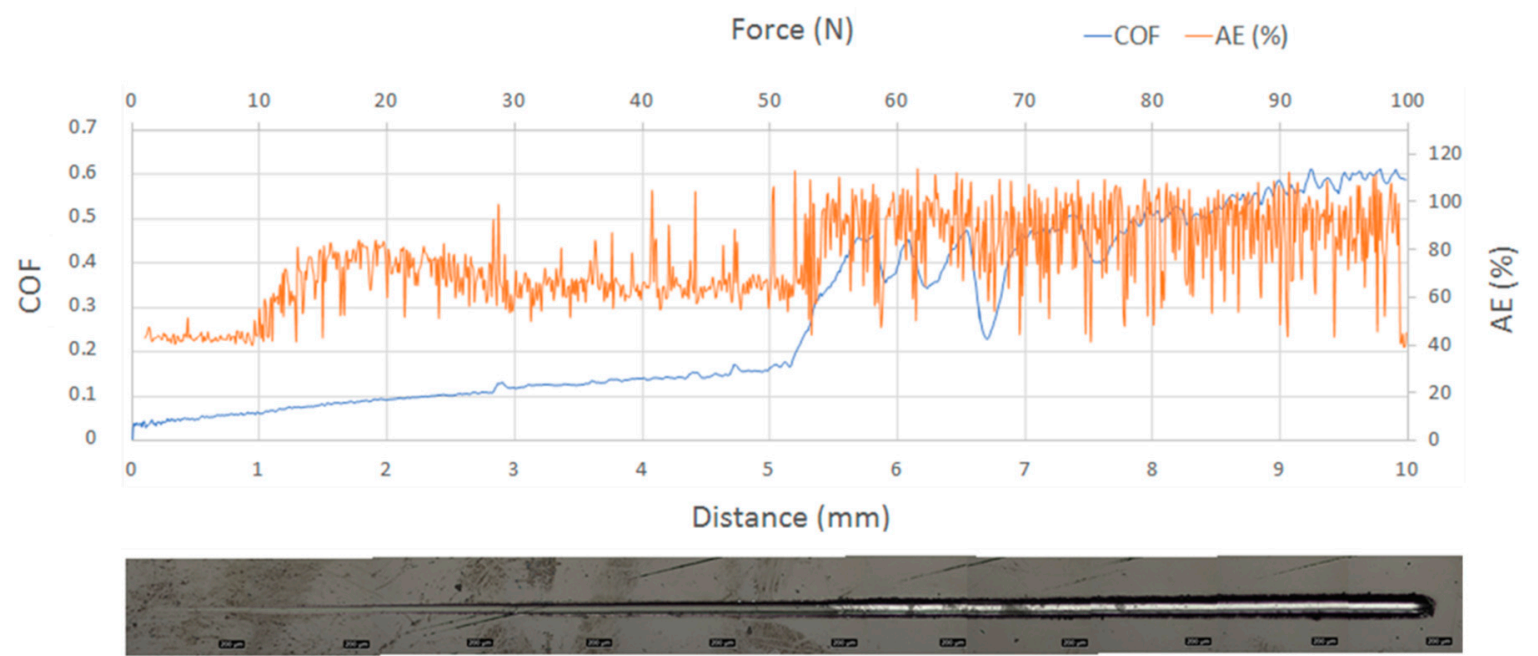

Figure 8. Nanoscratch test for WC:C coating. Evolution of the coefficient of friction (COF, blue plot) and the acoustic emission (AE, orange plot) vs. the indenter displacement, and optical micrograph of the scratch tracks.

Finally, the adhesion of both types of DLC coatings was also analyzed by the Daimler Benz test, using a conventional Rockwell $\mathrm{C}$ indentation tester, as can be observed in the optical micrographs in Figure 9. According to this, the ta-C DLC coating (Figure 9a) exhibited small delaminated parts at 
the border of the impact mark, which allowed classifying the system into the HF-2 grade. However, a notable difference can be appreciated in the WC:C DLC coating, where a few radial cracks were observed, enabling a classification into the highest HF-1 grade (Figure 9b) [35,36].
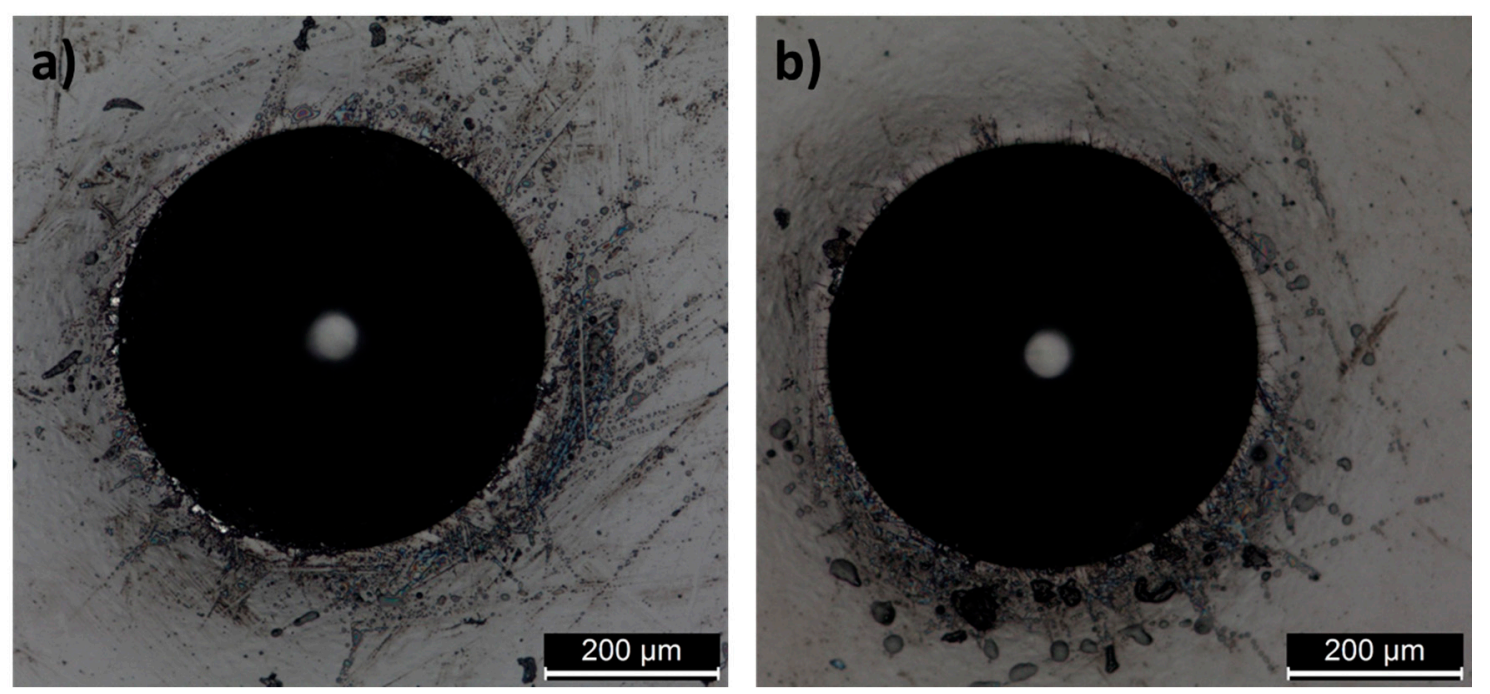

Figure 9. Aspects of the optical micrographs after the indentation Rockwell test impacts onto the ta-C DLC coating (a) and WC:C DLC coating (b).

\subsection{Friction and Wear Test}

The friction properties of the DLC coatings, as well as the reference substrate (1.2379 steel), were investigated using the pin-on-disc tribometer. The experimental results are shown in Figure 10. The steady coefficient of friction (COF) for the 1.2379 steel (uncoated reference sample) was around 0.85. As expected, the samples coated with DLC layers showed a considerable reduction in COF, showing values of 0.10 for $\mathrm{WC}: \mathrm{C}$ and 0.07 for ta-C. The results of friction coefficient are lower than those reported in Reference [37], where the friction coefficient of nitrogen-doped DLC coating increased steadily and finally reached a value of 0.2 , whereas that for the DLC sample reached a value of 0.3 at the end of the test. However, the friction coefficients are very similar to those reported in Reference [38]. In this work, it was corroborated that the resultant coefficients of friction are closely related to the content and crystal phases of carbon. An important aspect to remark is that approximately constant friction coefficients were observed for all coatings, indicating that none of them were completely worn out at the end of the test.

In addition, the width of the wear tracks was much lower for the DLC coatings than for the reference substrate. According to this, the uncoated 1.2379 steel presented a track width of around $1.111 \mathrm{~mm}$ on average, whereas the WC:C DLC track width was $438 \mu \mathrm{m}$ and the ta-C presented the lowest width value of $226 \mu \mathrm{m}$. In Figure 11, optical micrographs and confocal images showing the aspects of the resultant wear tracks for both DLC-coated samples are displayed. An aspect to remark is that the wear tracks of the sample coated with ta-C showed a surface with little abrasive wear, whereas the sample coated by WC:C showed the typical micro scratches of abrasive wear, which also matches with the more erratic friction curve of the latter. In any case, the dimensions of the resultant grooves for the coated samples were several orders of magnitude lower compared to the uncoated reference sample (1.2379 steel). The evaluation of the wear coefficient complies with the ASTM G99-95 standard, and it is a function of the loss volume around the whole track using the track width, normalized by the applied load and the total sliding distance. Results are summarized in Table 3. 

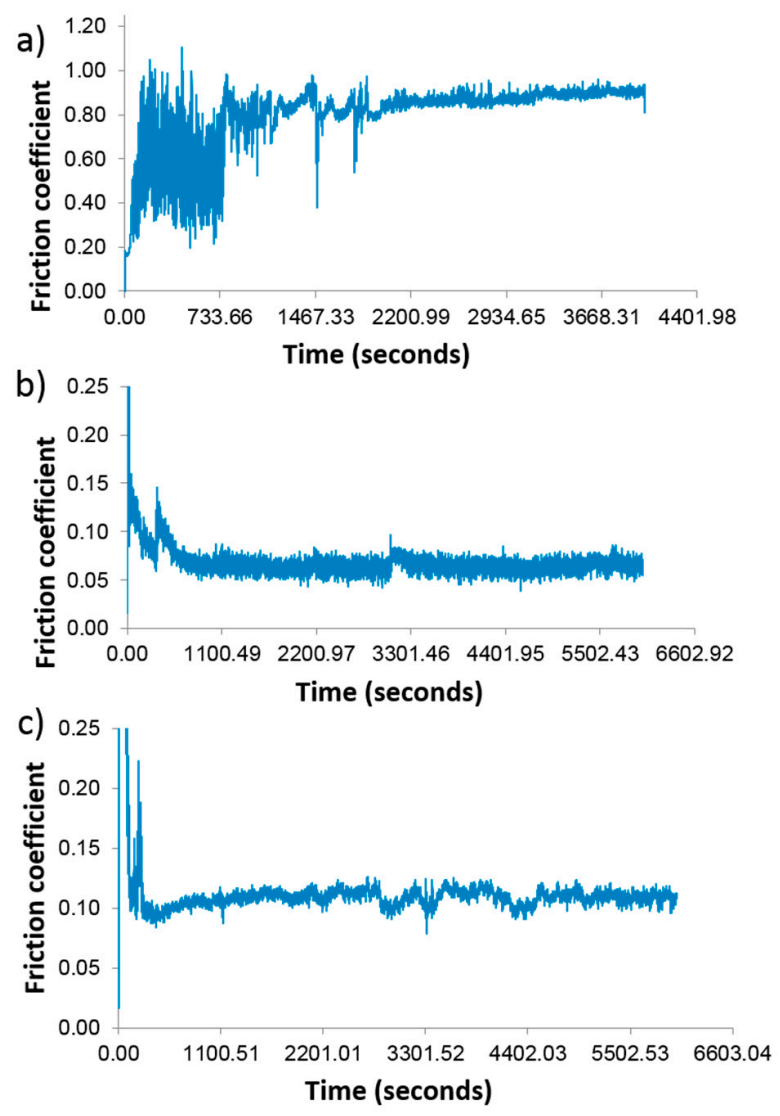

Figure 10. Friction coefficients of the uncoated reference substrate sample (a), ta-C DLC coating (b), and WC:C DLC coating (c).

a)
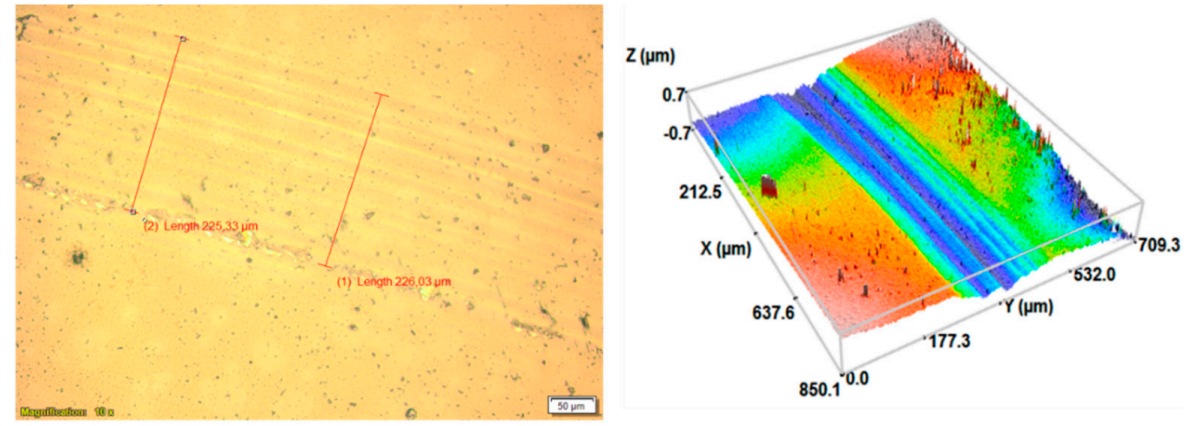

b)
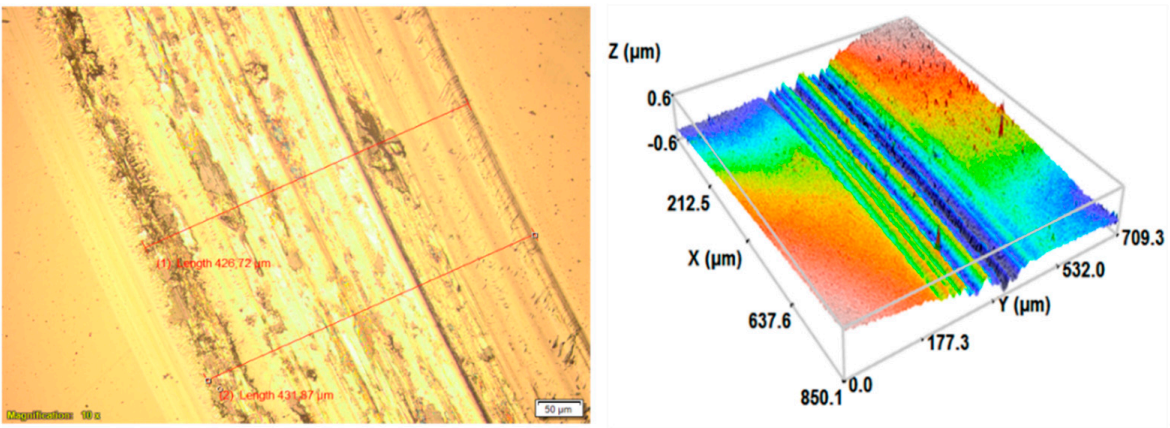

Figure 11. Aspects of the wear track obtained by optical and confocal microscopy after 20,000 cycles for the ta-C-coated sample (a) and for the WC:C-coated sample (b). 
Table 3 presents a summary of the different results related to the friction coefficient, width of the wear track, loss volume, and wear coefficient for each of the analyzed samples. The wear coefficient of the uncoated sample was $6.65 \times 10^{-5} \mathrm{~mm}^{3} / \mathrm{N} \cdot \mathrm{m}$, whereas DLC coatings showed values almost two orders of magnitude lower in comparison to the reference substrate, being $3.98 \times 10^{-7} \mathrm{~mm}^{3} / \mathrm{N} \cdot \mathrm{m}$ for the ta-C coating and $2.92 \times 10^{-6} \mathrm{~mm}^{3} / \mathrm{N} \cdot \mathrm{m}$ for the $\mathrm{WC}: \mathrm{C}$ coating. The result of the wear test reported for the WC:C coating is similar to the result found in Reference [35], showing a wear rate of $1.11 \times$ $10^{-6} \mathrm{~mm}^{3} / \mathrm{N} \cdot \mathrm{m}$ for the N-DLC coating or $1.88 \times 10^{-6} \mathrm{~mm}^{3} / \mathrm{N} \cdot \mathrm{m}$ for the DLC sample. However, higher results of wear rate were reported by Duminica et al. [22] $\left(3 \times 10^{-8} \mathrm{~mm}^{3} / \mathrm{N} \cdot \mathrm{m}\right)$, by Sun et al. [34] (6.37 $\left.\times 10^{-8} \mathrm{~mm}^{3} / \mathrm{N} \cdot \mathrm{m}\right)$, and by Wang et al. [36] $\left(7 \times 10^{-8} \mathrm{~mm}^{3} / \mathrm{N} \cdot \mathrm{m}\right)$.

Table 3. Summary of the experimental data on the friction coefficient, width of wear track, loss volume, and wear coefficient for the reference substrate (1.2379 steel), ta-C coating, and WC:C coating.

\begin{tabular}{ccccc}
\hline Sample & Friction Coefficient & Width of Wear Track $(\mu \mathrm{m})$ & Loss Volume $\left(\mathbf{m}^{\mathbf{3}}\right)$ & Wear Coefficient, $\mathbf{K}\left(\mathbf{m m} \mathbf{3}^{\mathbf{N}} \mathbf{N} \cdot \mathbf{m}\right)$ \\
\hline 1.2379 steel & 0.85 & 1.111 & $4.01 \times 10^{-9}$ & $6.65 \times 10^{-5}$ \\
ta-C coating & 0.07 & 226 & $2.40 \times 10^{-11}$ & $3.98 \times 10^{-7}$ \\
WC:C coating & 0.10 & 438 & $1.76 \times 10^{-10}$ & $2.92 \times 10^{-6}$ \\
\hline
\end{tabular}

Another method different from the one stated in ASTM G99-95 was also used to determine the wear coefficient. It relies on a direct measurement of the loss volume obtained by confocal perfilometric microscopy using the SENSOMAP program analysis. According to this, the wear results obtained by direct measurement of the loss volume showed a similar tendency with slight deviation between the coated and uncoated samples. Figure 12 presents a comparative graph of the values related to wear coefficient calculated by both methods using 10-mm (R10) and 12-mm (R12) alumina balls, showing good repeatability of the tribological tests.

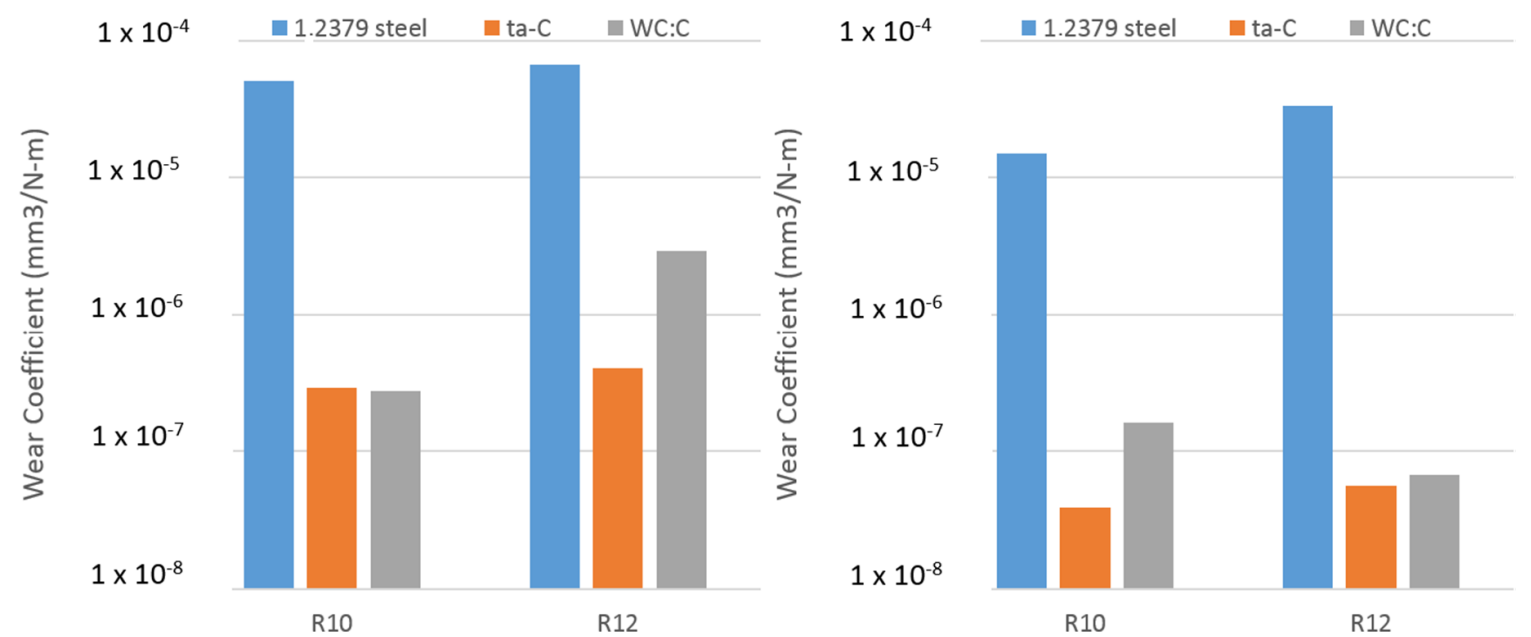

Figure 12. Summary of the experimental data on the friction coefficient, width of wear track, loss volume, and wear coefficient for the reference substrate (1.2379 steel), ta-C coating, and WC:C coating, obtained using the two different methods: ASTM G99 (left) and confocal microscopy (right).

Once the different DLC coatings obtained by HiPIMS were extensively examined, several aspects were remarked. First of all, the nanohardness values are in accordance with other previous works, showing the importance of $s p^{2} / s p^{3}$ ratio in determining the corresponding hardness. In addition, doping the DLC coating with W (WC:C) led to a decrease in the surface energy, with a consequent increase in its adhesion properties, thereby showing an LC2 of $40 \mathrm{~N}$ and LC3 of $60 \mathrm{~N}$ in comparison with the ta-C coating with an LC2 of $20 \mathrm{~N}$ and LC3 of $50 \mathrm{~N}$. Another important aspect is that, by using HiPIMS, it was possible to obtain very high resistance to plastic deformation $\left(H^{3} / E^{2}\right)$. Specifically, 0.15 and 0.45 were obtained for the samples doped with $\mathrm{W}$ and ta-C, respectively. The values of the 
samples doped with W (WC:C) are consistent with those found in the literature, while the values of the samples of ta-C are identical to those found by other authors. This aspect is due to the combined effect of a low value of the elastic modulus and the relatively high value of the nanohardness for this ta-C sample. Moreover, these interesting values of resistance to the plastic deformation enabled obtaining a low wear coefficient value $\left(3.98 \times 10^{-7} \mathrm{~mm}^{3} / \mathrm{N} \cdot \mathrm{m}\right.$ for ta-C versus $2.92 \times 10^{-6} \mathrm{~mm} / \mathrm{N} \cdot \mathrm{m}$ for WC:C) . Finally, regarding the measurement of the wear rate, it should be noted that the use of the two different methods (ASTM G99 and direct measurement of the loss volume by confocal microscopy) showed slight discrepancies, which can be associated with the small wear suffered by the alumina balls after 20,000 cycles in the pin-on-disc test, resulting in a truncated sphere, leading to smaller but possibly more realistic results.

\section{Conclusions}

In this work, two different DLC coatings, ta-C and WC:C, were used to coat a specific tool steel (1.2379 steel). The coatings were performed using the HiPIMS technique with positive pulses, which allowed obtaining very interesting tribological properties, such as a high resistance to the plastic deformation, as well as a high wear resistance. The following aspects must be highlighted:

- The nanohardness values were 30.6 GPa for the ta-C sample and 17.6 GPa for the WC:C sample.

- The elastic moduli found were very low, an issue associated with the high values of resistance to plastic deformation.

- The adhesion of the coatings was very high (corroborated by the scratch test), associated with the reduction in surface energy.

- The coefficient of friction (COF) against alumina for both coatings was very low in comparison with the reference substrate.

- Both DLC coatings showed very small wear coefficients, especially the ta-C sample with a value of $3.98 \times 10^{-7} \mathrm{~mm}^{3} / \mathrm{N} \cdot \mathrm{m}$, which was two orders of magnitude lower than the reference substrate $\left(6.65 \times 10^{-5} \mathrm{~mm}^{3} / \mathrm{N} \cdot \mathrm{m}\right)$, whereas the wear coefficient related to the WC:C sample was $2.92 \times 10^{-6}$ $\mathrm{mm}^{3} / \mathrm{N} \cdot \mathrm{m}$.

To sum up, the experimental results derived from the mechanical and tribological tests highlight these coatings, obtained by HIPIMS with positive pulses, as promising alternatives for industrial implementation, until now reserved for other types of coatings.

Author Contributions: Conceptualization, J.A.G., P.J.R., I.F. and J.A.S.; methodology, G.G.F.; formal analysis, J.A.G. and P.J.R.; investigation, J.A.G., P.J.R., E.B., J.A.S. and J.F.P.; writing —original draft preparation, J.A.G., and P.J.R.; writing - review and editing, J.A.G., P.J.R., J.A.S., J.F.P. and R.J.R. All authors have read and agreed to the published version of the manuscript.

Funding: This research received no external funding.

Conflicts of Interest: The authors declare no conflict of interest.

\section{References}

1. Bewilogua, K.; Hofmann, D. History of diamond-like carbon films-From first experiments to worldwide applications. Surf. Coat. Technol. 2014, 242, 214-225. [CrossRef]

2. Rodríguez, R.J.; García, J.A.; Martinez, R.; Lerga, B.; Rico, M.; Fuentes, G.G.; Guette, A.; Labruguere, C.; Lahaye, M. Tribological metal-carbon coatings deposited by PVD magnetron sputtering. Appl. Surf. Sci. 2004, 235, 53-59. [CrossRef]

3. Dai, M.; Zhou, K.; Yuan, Z.; Ding, Q.; Fu, Z. The cutting performance of diamond and DLC-coated cutting tools. Diam. Relat. Mater. 2000, 9, 1753-1757. [CrossRef]

4. Fukui, H.; Okida, J.; Omori, N.; Moriguchi, H.; Tsuda, K. Cutting performance of DLC coated tools in dry machining aluminum alloys. Surf. Coat. Technol. 2004, 187, 70-76. [CrossRef]

5. Podgornik, B.; Hogmark, S. Surface modification to improve friction and galling properties of forming tools. J. Mater. Process. Technol. 2006, 174, 334-341. [CrossRef] 
6. Hauert, R.; Thorwarth, K.; Thorwarth, G. An overview on diamond-like carbon coatings in medical applications. Surf. Coat. Technol. 2013, 233, 119-130. [CrossRef]

7. Treutler, C.P.O. Industrial use of plasma-deposited coatings for components of automotive fuel injection systems. Surf. Coat. Technol. 2005, 200, 1969-1975. [CrossRef]

8. Novikov, N.V.; Gontar, A.G.; Khandozhko, S.I.; Kutsay, A.M.; Tkach, V.N.; Gorokhov, V.Y.; Belitsky, G.M.; Vasinc, A.V. Protective diamond-like coatings for optical materials and electronic devices. Diam. Relat. Mater. 2000, 9, 792-795. [CrossRef]

9. Donnet, C.; Erdemir, A. New horizon in the tribology of diamondlike carbon films. Surf. Eng. 2008, 24, 399-401. [CrossRef]

10. Erdemir, A.; Donnet, C. Tribology of diamond-like carbon films: Recent progress and future prospects. J. Phys. D Appl. Phys. 2006, 39. [CrossRef]

11. Liao, W.-H.; Lin, C.-R.; Wei, D.-H.; Shen, Y.-R.; Li, Y.-C.; Lee, J.-A.; Liang, C.-Y. Concurrent improvement in biocompatibility and bioinertness of diamond-like carbon films with nitrogen doping. J. Biomed. Mater. Res. Part A 2012, 100, 3151-3156. [CrossRef] [PubMed]

12. Morshed, M.M.; McNamara, B.P.; Cameron, D.C.; Hashmi, M.S.J. Stress and adhesion in DLC coatings on 316L stainless steel deposited by a neutral beam source. J. Mater. Process. Technol. 2003, 141, 127-131. [CrossRef]

13. Mosaner, P.; Bonelli, M.; Miotello, A. Pulsed laser deposition of diamond-like carbon films: Reducing internal stress by thermal annealing. Appl. Surf. Sci. 2003, 208-209, 561-565. [CrossRef]

14. Schwingenschlögl, P.; Tenner, J.; Merklein, M. Tribological behavior of different tool steels and surface properties under hot stamping conditions. Key Eng. Mater. 2018, 767, 212-219. [CrossRef]

15. Sgarabotto, F.; Ghiotti, A.; Bruschi, S. Novel experimental set-up to investigate the wear of coatings for sheet metal forming tools. Key Eng. Mater. 2013, 554-557, 825-832. [CrossRef]

16. Lister, M. Vanadium carbide diffusion coatings for tool and die components. ASM Proc. Heat Treat. 2006, $2006,162-166$.

17. Janoss, B.J. PVD/CVD coatings for stamping and forming of stainless steels. In Technical Papers-Society of Manufacturing Engineers-All Series, Proceedings of the 1999 Conference Forming and Fabricating Stainless Steel, Springfield, MA, USA, 1999; Society of Manufacturing Engineers: Dearborn, MI, USA, 1999; pp. 99-199.

18. Dong, Y.; Zheng, K.; Fernandez, J.; Li, X.; Dong, H.; Lin, J. Experimental investigations on hot forming of AA6082 using advanced plasma nitrocarburised and CAPVD WC: C coated tools. J. Mater. Process. Technol. 2017, 240, 190-199. [CrossRef]

19. Incerti, L.; Rota, A.; Valeri, S.; Miguel, A.; García, J.A.; Rodríguez, R.J.; Osés, J. Nanostructured self-lubricating CrN-Ag films deposited by PVD arc discharge and magnetron sputtering. Vacuum 2011, 85, 1108-1113. [CrossRef]

20. Hovsepian, P.E.; Münz, W.-D.; Medlock, A.; Gregory, G. Combined cathodic arc/unbalanced magnetron grown $\mathrm{CrN} / \mathrm{NbN}$ superlattice coatings for applications in the cutlery industry. Surf. Coat. Technol. 2000, 133-134, 508-516. [CrossRef]

21. Waseem, B.; Alam, S.; Irfan, M.; Shahid, M.; Farooq, M.; Soomro, B.D.; Hashim, S.; Iqbal, R. Optimization and characterization of adhesion properties of DLC coatings on different substrates. Mater. Today Proc. 2015, 2, 5308-5312. [CrossRef]

22. Duminica, F.-D.; Belchi, R.; Libralesso, L.; Mercier, D. Investigation of Cr(N)/DLC multilayer coatings elaborated by PVD for high wear resistance and low friction applications. Surf. Coat. Technol. 2018, 337, 396-403. [CrossRef]

23. Moreno-Bárcenas, A.; Alvarado-Orozco, J.M.; Carmona, J.M.G.; Mondragón-Rodríguez, G.C.; González-Hernández, J.; García-García, A. Synergistic effect of plasma nitriding and bias voltage on the adhesion of diamond-like carbon coatings on M2 steel by PECVD. Surf. Coat. Technol. 2019, 374, 327-337. [CrossRef]

24. Marin, E.; Lanzutti, A.; Nakamura, M.; Zanocco, M.; Zhu, W.; Pezzotti, G.; Andreatt, F. Corrosion and scratch resistance of DLC coatings applied on chromium molybdenum steel. Surf. Coat. Technol. 2019, 378, 124944. [CrossRef]

25. Liu, L.; Wu, Z.; An, X.; Shao, T.; Xiao, S.; Cui, S.; Lin, H.; Fu, R.K.Y.; Tian, X.; Chu, P.K.; et al. Improved interfacial adhesion between TiAlN/DLC multi-layered coatings by controlling the morphology via bias. Surf. Coat. Technol. 2017, 331, 15-20. [CrossRef] 
26. Santiago, J.A.; Fernández-Martínez, I.; Wennberg, A.; Molina-Aldareguia, J.M.; Castillo-Rodríguez, M.; Rojas, T.C.; Sánchez-López, J.C.; González, M.U.; García-Martín, J.M.; Li, H.; et al. Adhesion enhancement of DLC hard coatings by HiPIMS metal ion etching pretreatment. Surf. Coat. Technol. 2018, 349, 787-796. [CrossRef]

27. Santiago, J.A.; Fernández-Martínez, I.; Kozák, T.; Capek, J.; Wennberg, A.; Molina-Aldareguia, J.M.; Bellido-González, V.; González-Arrabal, R.; Monclús, M.A. The influence of positive pulses on HiPIMS deposition of hard DLC coatings. Surf. Coat. Technol. 2019, 358, 43-49. [CrossRef]

28. Santiago, J.A.; Fernández-Martínez, I.; Sánchez-López, J.C.; Rojas, T.C.; Wennberg, A.; Bellido-González, V.; Molina-Aldareguia, J.M.; Monclús, M.A.; González-Arrabal, R. Tribomechanical properties of hard Cr-doped DLC coatings deposited by low-frequency HiPIMS. Surf. Coat. Technol. 2020, 382, 124899. [CrossRef]

29. García, J.A.; Rodríguez, R.J.; Martínez, R.; Fernández, C.; Fernández, A.; Payling, R. Depth profiling of industrial surface treatments by rf and dc glow discharge spectrometry. Appl. Surf. Sci. 2004, 235, 97-102. [CrossRef]

30. Vidakis, N.; Antoniadis, A.; Bilalis, N. The VDI 3198 indentation test evaluation of a reliable qualitative control for layered compounds. J. Mater. Process. Technol. 2003, 143-144, 481-485. [CrossRef]

31. Oliver, W.C.; Pharr, G.M. Nanoindentation in materials research: Past, present, and future. MRS Bull. 2010, 35, 897-907. [CrossRef]

32. Oliver, W.C.; Pharr, G.M. Measurement of hardness and elastic modulus by instrumented indentation: Advances in understanding and refinements to methodology. J. Mater. Res. 2004, 19, 3-20. [CrossRef]

33. Ferrari, A.C.; Robertson, J. Interpretation of Raman spectra of disordered and amorphous carbon. Phys. Rev. B 2000, 61, 14095-14107. [CrossRef]

34. Sun, W.; Li, M.; Wu, M.; Hu, J. Uniformity of Si-containing diamond-like carbon films deposited at different positions by mesh hollow cathode discharge. Results Phys. 2019, 14, 102480. [CrossRef]

35. Bouzakis, K.-D.; Vidakis, N.; Michailidis, N.; Leyendecker, T.; Erkens, G.; Fuss, G. Quantification of properties modification and cutting performance of $\left(\mathrm{Ti}_{1-\mathrm{x}} \mathrm{Al}_{\mathrm{x}}\right) \mathrm{N}$ coatings at elevated temperatures. Surf. Coat. Technol. 1999, 120-121, 34-43. [CrossRef]

36. Mercier, D.; Mandrillon, V.; Parry, G.; Verdier, M.; Estevez, R.; Bréchet, Y.; Maindron, T. Investigation of the fracture of very thin amorphous alumina film during spherical nanoindentation. Thin Solid Films 2017, 638, 34-47. [CrossRef]

37. Sharifahmadian, O.; Mahboubi, F. A comparative study of microstructural and tribological properties of N-DLC/DLC double layer and single layer coatings deposited by DC-pulsed PACVD process. Ceram. Int. 2019, 45, 7736-7742. [CrossRef]

38. Wang, L.; Li, L.; Kuang, X. Effect of substrate bias on microstructure and mechanical properties of WC-DLC coatings deposited by HiPIMS. Surf. Coat. Technol. 2018, 352, 33-41. [CrossRef] 